\title{
The prognostic value of the strong ion gap in acute pancreatitis
}

Xiao Shen, MD ${ }^{1 \mathrm{a}}$, Lu Ke, MD, $\mathrm{PhD}^{1 \mathrm{a}^{* * *}}$, Dongliang Yang, $\mathrm{MD}^{1}$, Jing Sun, $\mathrm{MD}^{2}$,

Zhihui Tong, MD, $\mathrm{PhD}^{1}$, Baiqiang Li, $\mathrm{MD}^{1}$, Gang Li, $\mathrm{MD}^{1}$, Weiqin Li, $\mathrm{MD}, \mathrm{PhD}^{1 *}$,

Jieshou Li, $\mathrm{MD}, \mathrm{PhD}^{2}$, Rinaldo Bellomo, $\mathrm{MD}^{3}$.

1. Surgical Intensive Care Unit (SICU), Department of General Surgery, Jinling Hospital, Medical School of Nanjing University, No.305 Zhongshan East Road, Nanjing, China.

2. Department of General Surgery, Jinling Hospital, Medical School of Nanjing University, No.305 Zhongshan East Road, Nanjing, China.

3. Department of Intensive Care, Austin Hospital and The University of Melbourne, 145 Studley Road, PO Box 5555, Heidelberg, Victoria, Australia. a These authors contribute equally to the paper.

Correspondence to:

* Weiqin Li, Surgical Intensive Care Unit (SICU), Department of General Surgery, Jinling Hospital, Medical School of Nanjing University. No.305 Zhongshan East

Road, Nanjing, China. Fax: +86-25-80861655, Tel: +8613951839654, E-mail: njzy_pancrea@163.com

** Lu Ke, Surgical Intensive Care Unit (SICU), Department of General Surgery, Jinling Hospital, Medical School of Nanjing University. No.305 Zhongshan East 
Road, Nanjing, China. Fax: +86-25-80861655, Tel: +8618626427913, E-mail: kkb9832@163.com 


\begin{abstract}
Purpose: In this study, we aimed to evaluate the predictive value of Stewart-derived parameters for the development of severe type of acute pancreatitis (AP) and for AP-related mortality.
\end{abstract}

Methods: We studied 186 patients admitted to the hospital with AP. We performed blood gas and biochemical analysis for each patient on admission. We calculated multiple metrics according to the Stewart's acid-base theory and assessed their accuracy as predictors of AP severity and mortality.

Results: Of the 186 patients presenting with AP, 85 (45.7\%) developed severe AP and $33(17.7 \%)$ died during hospitalization. Patients with severe AP had significantly higher median strong ion gap (SIG) than patients with mild or moderate AP (7.88 vs. $2.11 \mathrm{mEq} / \mathrm{L}, \mathrm{p}<0.001)$. In multivariate logistic regression analysis, SIG had an odds ratio $(\mathrm{OR})$ of $1.56(\mathrm{p}<0.001)$. Additionally, SIG had good predictive power for mortality (OR: 1.26, $\mathrm{p}=0.014)$ as well as AKI (OR: 1.34, $\mathrm{p}<0.001)$.

Conclusions: In a cohort of patients with AP, SIG was a strong independent predictor of severity and mortality. Besides, SIG might also be an early marker for AKI in AP patients. Additional research is needed to identify the nature of the unmeasured anions responsible for such findings.

Key words: acute pancreatitis; strong ion gap; outcome prediction; anion gap; lactate; albumin. 


\section{Introduction}

Acid-base disorders are common in critically ill patients and associated with high mortality [1-3]. In patients with acute pancreatitis (AP), such disorders are often present on admission to the intensive care unit (ICU)[4, 5]. The epidemiology and clinical significance of such disorders in AP, however, is poorly understood.

The traditional method for interpreting acid-base disorders is based on the Henderson-Hasselbalch equation[6], which is then coupled with the anion gap (AG)[7] and clinical assessment to define the presence of specific metabolic or respiratory acid-base states. However, the traditional method has been criticized for not taking into account the impact of hypoalbuminemia, disorders of phosphatemia, and the presence and impact of unmeasured anions when used improperly (without correction for hypoalbuminemia) [8-10]. Stewart's approach offers an alternative paradigm for the interpretation of acid-base disorders and allows quantification of the effects of changes in strong ion difference (SID), albumin and phosphate levels, and unmeasured anions (strong ion gap - SIG).

Two studies have shown that SID and SIG correlate with hospital mortality in trauma patients $[11,12]$. Moreover, the prognostic value of SIG was also confirmed in other critically ill patients [13]. More recently, Sharma also found that arterial $\mathrm{pH}$, bicarbonate levels and base deficit at presentation were early markers for predicting 
adverse outcome in acute pancreatitis[5]. However, no information exists on the predictive value of acid-base variables as estimated by the Stewart approach in patients with AP.

The purpose of our investigation was to evaluate how acid-base variables obtained at the earliest stages of AP and analyzed according to the Stewart model may help predict subsequent AP severity and AP-related mortality.

\section{Materials and Methods}

\section{Patients and materials}

We conducted a retrospective, cohort study in the Surgical Intensive Care Unit (SICU) of Jinling Hospital, Nanjing, China, a tertiary referral center for the treatment of acute pancreatitis. The data collection for this study was approved by the Institutional Review Board of Jinling Hospital. Patients with a primary diagnosis of AP admitted to our center from September 2010 to June 2014 were screened for potential inclusion. Diagnosis of AP required two of the three following criteria: 1) Abdominal pain consistent with the disease; 2) Serum amylase and/or lipase greater than three times the upper limit of normal, and/or; 3) Characteristic findings from abdominal ultrasonography, contrast-enhanced computed tomographic (CECT) and/or magnetic resonance imaging $(\mathrm{MRI})[14,15]$. 
The study inclusion criteria included 1) adult patient with AP; 2) admission to our center within $72 \mathrm{~h}$ of AP onset and 3) available blood gas and laboratory assessments on admission to our center. Patients with co-morbidities that might affect their blood gas results (e.g. diabetic ketoacidosis, chronic renal failure), patients who had been previously treated in another hospital prior to transfer to our center or those who had received $\geqslant 400 \mathrm{ml}$ intravenous fluids before admission to our center were excluded.

A heparinized arterial blood sample was collected on admission for all the study patients and analyzed in the ICU blood-gas analyzer (ABL800 Blood Gas Analyzer, Radiometer, Copenhagen, Denmark). Values for $\mathrm{pH}$, partial pressure of oxygen and carbon dioxide $\left(\mathrm{PaO}_{2}\right.$ and $\left.\mathrm{PaCO}_{2}\right)$, serum levels of ionized calcium $\left(\mathrm{iCa}^{++}\right)$and lactate were obtained from the results of blood gas analysis. At the same time, additional blood samples were taken for routine biochemical analysis. Biochemical analysis was performed in the central laboratory of our hospital on an Aeroset analyzer (Hitachi 7060 Automatic Biochemical Analyzer, Tokyo, Japan) for $\mathrm{Na}^{+}, \mathrm{K}^{+}, \mathrm{Cl}^{-}, \mathrm{Mg}^{++}$, albumin, blood urea nitrogen (BUN) and creatinine. Blood routine testing was also carried out in the central laboratory for hemoglobin, hematocrit and platelet using an automatic blood cell analyzer (CELL-DYN3700, Chicago, Abbott). After consent was obtained, thirteen health volunteers from the medical and nursing staff were also studied in the same way and used as controls. The volunteer group consisted of nine males and four females, with a median age of 30 (range: 24-53) years. 


\section{Data collection}

Demographic information (age, Acute Physiology and Chronic Health Evaluation [APACHE] II, Bedside Index For Severity In Acute Pancreatitis [BISAP] and Sequential Organ Failure Assessment [SOFA] score, CT severity index, gender, etiology of acute pancreatitis, etc.), arterial blood gases, and biochemical data were collected. Severity of AP was defined according to the 2012 revision of the Atlanta classification[15]. Briefly, mild, moderate and severe types of AP were classified based on the presence of organ failure and complications.

Hospital mortality, length of hospital and ICU stays as well as the incidence of organ failure and complications were recorded for outcome comparison. Organ failure was defined as a score of 2 or more using the modified Marshall scoring system in the respiratory, cardiovascular and renal systems according to the revised Atlanta classification criteria[16]. The diagnostic criteria for local and systemic complications were those of the Atlanta classification[15].

\section{Acid-base analysis}

According to data from blood gas analysis, blood routine and biochemical tests at admission, the levels of bicarbonate and $\mathrm{AG}$ and $\mathrm{AG}_{\text {corr }}$ were calculated using the 
Henderson-Hasselbalch equation[17] and standard base excess (SBE) was calculated using the Siggaard-Andersen formulae[18]:

$$
\mathrm{pH}=6.1+\log \left(\left[\mathrm{HCO}_{3}^{-}\right] /\left[0.0301 \times \mathrm{PaCO}_{2}\right]\right)
$$

$\mathrm{PaCO}_{2}$ was in $\mathrm{mmHg}$ and $\mathrm{HCO}_{3}{ }^{-}$in milliequivalent per liter.

$$
\begin{gathered}
\mathrm{AG}=\left[\mathrm{Na}^{+}\right]+\left[\mathrm{K}^{+}\right]-\left[\mathrm{Cl}^{-}\right]-\left[\mathrm{HCO}_{3}{ }^{-}\right] \\
\mathrm{AG}_{\mathrm{corr}}=\mathrm{AG}+0.25 \times(40-[\text { Albumin }])-[\text { Lactate }]
\end{gathered}
$$

$\mathrm{Na}^{+}, \mathrm{K}^{+}, \mathrm{Cl}^{-}, \mathrm{HCO}_{3}{ }^{-}, \mathrm{AG}$ were in milliequivalent per liter, Albumin in $\mathrm{g} / \mathrm{L}$ and Lactate in $\mathrm{mmol} / \mathrm{L}$.

$$
\mathrm{SBE}=0.02786 \times \mathrm{PaCO}_{2} \times 10^{(\mathrm{pH}-6.1)}+13.77 \times \mathrm{pH}-124.58
$$

$\mathrm{PaCO}_{2}$ was in $\mathrm{mmHg}$.

Apparent and effective SID (SIDa, SIDe) and SIG were calculated according to the modified Stewart's method[8, 19]. Calculations were performed as described by the following formulas:

$$
\mathrm{SIDa}=\left[\mathrm{Na}^{+}\right]+\left[\mathrm{K}^{+}\right]+\left[\mathrm{Mg}^{2+}\right]+\left[\mathrm{Ca}^{2+}\right]-\left[\mathrm{Cl}^{-}\right]-[\text {Lactate }]
$$

All concentrations were in milliequivalent per liter.

$$
\begin{gathered}
\text { SIDe }=2.46 \times 10^{(\mathrm{pH}-8)} \times \mathrm{PaCO}_{2}+[\text { Albumin }] \times(0.12 \times \mathrm{pH}-0.631)+[\text { Phosphate }] \times \\
0.309 \times \mathrm{pH}-0.469
\end{gathered}
$$

$\mathrm{PaCO}_{2}$ was in mmHg, Albumin in $\mathrm{g} / \mathrm{L}$ and Phosphate in mmol/L. 


$$
\mathrm{SIG}=\mathrm{SIDa}-\mathrm{SIDe}
$$

All concentrations were in milliequivalent per liter.

\section{Statistical analysis}

Statistical analyses were performed using the SPSS 22.0 statistical software package (IBM Analytics, Armonk, NY). Data are presented as absolute values, proportions or median plus interquartile range (IQR). The Chi-square test was used for categorical variables and Student's t test used for continuous variables. Logistic regression was used to identify relationships between variables. Further multivariate stepwise logistic regression only included the variables that were statistically significant in the univariate logistic regression. Afterwards, a receiver operating characteristic (ROC) curve was constructed to evaluate the potential ability of each variable to predict severity or mortality of AP. Furthermore, to analyze the potential factors that may relate to the levels of SIG, a univariate linear regression analysis including the variables that were theoretically associated with SIG was performed. Variables showing significance in the univariate analysis were included for multivariate stepwise analysis. A p value of $<0.05$ was considered statistically significant. 


\section{Results}

During the study period, 980 patients with acute pancreatitis were screened and 794 were excluded (see the details in Figure 1), leaving 186 consecutive patients for analysis. Their demographic data are shown in Table 1 . The study patients had an overall mortality of $17.7 \%$. In total, $24(72.7 \%)$ patients died of septic shock and multiple organ failure (MOF), 4 (12.1\%) died of uncontrolled intra-abdominal hemorrhage, $2(6.1 \%)$ died of tracheal hemorrhage, and the last three died of middle cerebral artery aneurysm rupture (3.0\%), pulmonary embolism (3.0\%) and unexplained cardiac arrest (3.0\%), respectively. Male patients were dominant at 67.7\%. Diabetes mellitus was one of the most common co-morbidities in these patients, occurring mostly among those with hypertriglyceridemia-induced pancreatitis $(69 / 85,81.2 \%)$. The median length of hospital stay and ICU stay were 12.0 (IQR, 7.0 to 22.0 ) and 7.0 (IQR, 4.0 to 15.0 ) days, respectively.

Patients were divided into two groups on the basis of AP severity: severe $(n=85)$ and mild-moderate $(n=101)$ group (Table 1). Patients in the two groups showed no significant difference in age and gender distribution, but the severe group had a higher body mass index (BMI), APACHE II, BISAP and SOFA score as well as CT severity index. Patients with severe AP had longer length of hospital and ICU stay and much higher mortality. All the patients who died during hospitalization were in the severe 
group. The incidence of transient $(<48 \mathrm{~h})$ organ failure was $12.9 \%(13 / 101)$ in the mild-moderate group. Among all the AP patients, lung and kidney were the two organs most commonly involved. Overall, 55 (64.7\%) patients in the severe group developed MOF during hospitalization, primarily a combination of acute respiratory distress syndrome (ARDS) and acute kidney injury (AKI). As for local complications, intra-abdominal hemorrhage $(21 / 85,24.7 \%)$ and intra-abdominal hypertension (IAH) $(18 / 85,21.2 \%)$ were the two most common ones, followed by fistula formation $(12 / 85$, $14.1 \%)$, of which, colonic fistula was predominant $(8 / 12,66.7 \%)$.

Table 2 presented the data acquired in assessing acid-base balance and the calculated metrics in both patients and volunteers. As expected, patients in both groups had a wide range of acid-base abnormalities: $30(29.7 \%)$ patients in the mild-moderate group and 37 (43.5\%) patients in the severe group had an abnormal $\mathrm{pH}$ on admission. Only one moderate AP patient had an initial $\mathrm{pH}<7.25$. Additionally, 30 (29.7\%) patients in the mild-moderate group and $56(65.9 \%)$ patients in the severe group developed hypoalbuminemia $(<35 \mathrm{~g} / \mathrm{L})$.

Patients in the severe group showed significant higher SIG (7.88 [IQR, 5.25 to $10.00] \mathrm{mEq} / \mathrm{L})$, than those in mild-moderate group (2.11 [IQR, 0.97 to 4.15$] \mathrm{mEq} / \mathrm{L}$, $\mathrm{p}<0.001$ ) (Figure 2). In the healthy volunteers (median age: 30 [range: 24-53] years 
old), the median SIG was 0.22 (IQR, -0.50 to 0.84$) \mathrm{mEq} / \mathrm{L}$, markedly lower than that in AP patients. Significant differences in $\mathrm{pH}, \mathrm{SBE}, \mathrm{AG}, \mathrm{AG}_{\mathrm{corr}}$, lactate, SIDa, SIDe, $\mathrm{Na}^{+}, \mathrm{K}^{+}, \mathrm{Cl}^{-}, \mathrm{iCa}^{++}, \mathrm{HCO}_{3}{ }^{-}$, albumin, hematocrit, hemoglobin, BUN and creatinine were also detected between mild-moderate and severe groups (Table 2).

Univariate logistic regression (Supplementary Table 1) showed correlations between AP severity and BISAP, SOFA, APACHE II score, CT severity index, hypertriglyceridemia, $\mathrm{pH}, \mathrm{Na}^{+}, \mathrm{K}^{+}, \mathrm{iCa}^{++}, \mathrm{Cl}^{-}$, lactate, $\mathrm{SBE}, \mathrm{HCO}_{3}{ }^{-}$, SIDa, SIDe, $\mathrm{SIG}$, AG, $\mathrm{AG}_{\text {corr }}$, albumin, hemoglobin, hematocrit, BUN as well as creatinine. Taking these variables into the multivariate stepwise logistic regression analysis for severity prediction (Table 3), significant independent correlations between disease severity and SOFA score, APACHE II score, SIG and $\mathrm{Na}^{+}$were found.

The area under the ROC curves was 0.91 (95\% CI: 0.86-0.95, p<0.001) for SIG, suggesting excellent predictive value for severe AP. The sensitivity and specificity of SIG were $84.4 \%$ and $82.0 \%$, respectively. In contrast, the area under the ROC curve values for $\mathrm{Na}^{+}$, APACHE II and SOFA score were a bit lower, $0.71,0.87$ and 0.82 separately.

Besides, we also compared survivors and non-survivors (Supplementary Table 2). Results showed significant difference in $\mathrm{pH}, \mathrm{SBE}, \mathrm{AG}, \mathrm{AG}_{\mathrm{corr}}, \mathrm{SIDe}, \mathrm{SIG}, \mathrm{Na}^{+}, \mathrm{K}^{+}$, 
$\mathrm{Cl}^{-}, \mathrm{Mg}^{++}, \mathrm{HCO}_{3}{ }^{-}$, albumin, hematocrit, hemoglobin, BUN and creatinine. All non-survivors but one $(32 / 33,97.0 \%)$ developed AKI during the initial stage of AP. Significant correlations between mortality and BISAP, SOFA and APACHE II score, CT severity index, $\mathrm{pH}, \mathrm{Na}^{+}, \mathrm{K}^{+}, \mathrm{Mg}^{++}, \mathrm{Cl}^{-}$, lactate, $\mathrm{SBE}, \mathrm{HCO}_{3}{ }^{-}$, SIDe, $\mathrm{SIG}, \mathrm{AG}$, $\mathrm{AG}_{\text {corr, }}$ albumin, hemoglobin, hematocrit, $\mathrm{BUN}$ as well as creatinine were seen on univariate logistic regression analysis (Supplementary Table 3).

Further multivariate logistic regression analysis (Supplementary Table 4) suggested significant correlations between mortality and APACHE II score, $\mathrm{Cl}^{-}$, albumin and SIG (odds ratio: $2.00,1.45,0.67,1.26$ ). The area under the ROC curves revealed that SIG (0.87) had moderate predictive power for mortality, lower than APACHE II score but higher than albumin and $\mathrm{Cl}^{-}$. Its sensitivity was $84.8 \%$ and its specificity was $78.3 \%$.

In addition, we also evaluated the predictive accuracy of SIG for AKI in AP patients. Serum levels of SIG were significantly higher in the patients with AKI than those without (8.28 [IQR, 5.76 to 10.37$] \mathrm{mEq} / \mathrm{L}$ vs. 2.65 [IQR, 1.19 to 5.33$] \mathrm{mEq} / \mathrm{L}$, $\mathrm{p}<0.001)$. Univariate logistic regression analysis suggested that AKI was strongly correlated with APACHE II score, hypertriglyceridemia, $\mathrm{pH}, \mathrm{Na}^{+}, \mathrm{K}^{+}, \mathrm{iCa}^{++}, \mathrm{Mg}^{++}$, phosphate, $\mathrm{Cl}^{-}$, lactate, $\mathrm{SBE}, \mathrm{HCO}_{3}{ }^{-}$, SIDe, $\mathrm{SIG}, \mathrm{AG}, \mathrm{AG}_{\mathrm{corr}}$, albumin, hemoglobin and hematocrit (Supplementary Table 5). Subsequent multivariate analysis revealed strong 
correlations between AKI and APACHE II score as well as SIG (Odds ratios were: 1.51 and 1.34, respectively) (Supplementary Table 6). The area under the ROC curves also indicated that SIG (0.88) had moderate predictive power for AKI, although a little bit lower than APACHE II score.

Univariate linear logistic regression models indicated that SBE, AG, $\mathrm{AG}_{\text {corr, }}$, lactate, phosphate, $\mathrm{HCO}_{3}{ }^{-}$, albumin, $\mathrm{BUN}$ and creatinine levels during admission were significantly associated with SIG (Table 4). After multivariate analysis, as expected, SBE, $\mathrm{AG}_{\text {corr }}$, phosphate, $\mathrm{HCO}_{3}{ }^{-}$and albumin remained independently and significantly associated with SIG.

\section{Discussion}

\section{Key findings}

We conducted a retrospective observational study to identify predictors of severity and outcome in a large cohort of AP patients from a tertiary referral center for pancreatitis in China before fluid resuscitation. We aimed to evaluate whether the Stewart analysis might help predict severity, mortality as well as AKI in adult AP patients with simple and routine clinical tests. Our results suggested that SIG was an accurate predictor of severity of acute pancreatitis and a moderate predictor of 
mortality and AP-related AKI. For both severity and mortality, SIG was proved to be the strongest predictor and outperformed many other traditionally used markers.

Relationship to previous studies

$\mathrm{AG}$ and base excess (BE) are commonly used to assess acid-base disturbances in clinical practice[20, 21]. The predictive power of AG and BE for mortality had been evaluated in the literature in different subsets of patients with controversial results $[20$, 22-24]. The main reason might be that AG lacks sensitivity and specificity due to oversimplification not taking into account the influence of albumin and phosphate. In this way, albumin and lactate-corrected $\mathrm{AG}\left(\mathrm{AG}_{\mathrm{corr}}\right)$ might be more appropriate for the detection of unmeasured anions in critically ill patients. However, although the accuracy of albumin and $\mathrm{AG}_{\text {corr }}$ was much more higher than $\mathrm{AG}$, its predictive values in disease severity and mortality was still lower than SIG as it has not entered into the final equations of the multivariate regression analysis for disease severity as well as mortality, probably due to the ignorance of the effect of phosphate on acid-base equilibrium. A recent study by Moviat et al. demonstrated that Stewart's acid-base analysis was able to uncover underlying mixed metabolic acid-base disorders in an ICU population with otherwise no apparent acid-base abnormalities[25]. However, owing to its relatively complex nature, Stewart's approach is still not widely used or fully accepted by many clinicians. 
The prognostic values of Stewart's parameters in the critically ill patients have been assessed in many clinical sets. The study conducted by Story et al. [26] suggested that the Stewart approach had predictive power for mortality. Two studies carried out by Cusack et al. and Rocktaeschel et al. indicated that unmeasured anions calculated as SIG had some, but limited prognostic value for mortality in general critically ill patients[3, 27]. Antonini et al. compared the AG and Stewart's variables in 136 ICU patients and demonstrated that metabolic acidosis induced by unmeasured anions was closely correlated with late mortality[28]. In general, the predictive power of SIG was not clearly identified in these critically ill patients due to the heterogeneity of the population in those studies. However, in other more homogeneous populations, such as patients with trauma and cardiac disease, SIG was a strong and accurate predictor of outcome $[11,29,30]$.

To our knowledge, this is the first study focusing on the prognostic value of Stewart's analysis in patients with acute pancreatitis. Sharma et al. evaluated the predictive power of arterial blood gas parameters using conventional methodology in 205 AP patients[5] with a mortality rate of $14.6 \%$, similar to our study. The authors found that lower arterial $\mathrm{pH}$, bicarbonate level and higher base deficit on admission predicted an adverse outcome in patients with acute pancreatitis and the area under 
ROC curve was 0.77 (95\% confidence interval [CI]: 0.66-0.88), 0.71 (95\% CI:

0.62-0.79) and 0.78 (95\% CI: 0.69-0.87) for the three parameters. However, many patients presented with hypoalbuminemia and hyperlactatemia in the early stage of acute pancreatitis and these variables were not taken into consideration. In contrast, our study used the Stewart method, which takes the influence of albumin and unmeasured anions into account. In addition, we also compared the discriminating power of SIG in predicting severity, mortality and AP-related AKI. We found that the accuracy of SIG was excellent for predicting subsequent disease severity, which is of great importance in triaging and treating AP $[4,31,32]$. Given that SIG could be easily calculated with simple and inexpensive blood tests right after hospital admission, its clinical use is of significant potential.

The exact sources of the unmeasured anions are likely multifactorial and still unclear. A previous study identified the liver as a major source of unidentified anions in canine models of sepsis[33]. However, in the case of acute pancreatitis, hypoperfusion and microcirculation disturbance might be the main reasons for elevated unmeasured anions[34]. Moreover, the most commonly involved organs are lung and kidney, not liver[35]. The significantly elevated levels of BUN and creatinine, suggest that failed renal excretion of unmeasured anions may, at least in part, explain such SIG. This hypothesis is partly supported by data from Moviat et al. 
showing that increased creatinine levels were independently related to a high SIG[25]. An association between creatinine and SIG was also detected in our study. In addition, similar to the study by Zheng et al., we also found a close relationship between SIG and AKI in the population of AP patients, indicating that SIG might also be regarded as an early indictor for AKI in AP patients[36]. An observational conducted by Moviat et al. examined the chemical nature of unmeasured anions in critically ill patients with metabolic acidosis by ion-exchange column chromatography, reverse-phase high-performance liquid chromatography, and gas chromatography/mass spectrometry and the results showed that amino acids, uric acid organ acids accounted for part of SIG in those patients with a metabolic acidosis[37]. Unfortunately, we did not measure uric acid in our patients. Further studies are needed to identify the nature of such unmeasured anions.

\section{Study implications}

Our study provides evidence that the SIG can be used to estimate the likely subsequent severity of pancreatitis with an excellent level of accuracy. Given the importance of estimating likely subsequent severity in the triage and treatment of these patients and their referral to appropriate centers, our findings imply that patients presenting with pancreatitis should be evaluated by calculation of their SIG. The 
finding that SIG also predicts mortality provides further justification for its early measurement in these patients for the purpose of prognosis and risk stratification.

\section{Strengths and limitations}

Our study has several strengths. It assessed a large cohort of patients with a single condition providing a degree of robustness to our findings. It used all necessary variables to estimate the relevant Stewart parameters and the SIG value. It found a clear predictive value for SIG in estimating subsequent severity and confirmed its usefulness by assessing its ability to predict mortality and AP-related AKI. The findings have significant implications for the stratification and management of these patients. However, our study also carries some limitations. First, it was retrospective in design leading to the risk of selection bias. However, the inclusion and exclusion criteria were well defined before the study was initiated to minimize such bias. Second, the number of the non-survivors was relatively small and this affects the precision of our estimates. However, even substantial modifications of up to $10 \%$ in predictive power would still leave the SIG as a valuable tool. Moreover, such lack of precision should not privilege the SIG and should similarly affect other predictors of outcome. Third, due to the nature of our hospital as a tertiary referral center, a large number of critically ill patients, who were treated in other hospitals before admission, 
were excluded from analysis. However, our findings remain relevant to other tertiary referral centers, which may receive similar patients.

To better verify our hypothesis, further prospective study has been designed to measure the main anions accounted for elevated SIG in patients with mild and severe $\mathrm{AP}$ and find out its role in the pathological process of AP.

\section{Conclusions}

In this study, we assessed the predictive value of the SIG in patients with acute pancreatitis. Our study demonstrated that an elevated SIG was a common phenomenon at the early stage of severe acute pancreatitis, that it was independently correlated with adverse outcomes and that it was an accurate predictor of subsequent severity and mortality, suggesting that it could be used in the triage, risk stratification, management and prognosis of such patients in the future.

\section{Acknowledgements}

This study was supported by the National Science Foundation of China (81300360).

The funding agency had no role in study design, the collection of data, in the interpretation of data, in the writing of the article, or in the decision to submit the article for publication. 


\section{Reference}

1. Gunnerson, K.J. and J.A. Kellum, Acid-base and electrolyte analysis in critically ill patients: are we ready for the new millennium? Curr Opin Crit Care, 2003. 9(6): p. 468-73.

2. Boniatti, M.M., et al., Acid-base disorders evaluation in critically ill patients: we can improve our diagnostic ability. Intensive Care Med, 2009. 35(8): p. 1377-82.

3. Rocktaeschel, J., et al., Unmeasured anions in critically ill patients: can they predict mortality? Crit Care Med, 2003. 31(8): p. 2131-6.

4. Savel'ev, V.S. and V.G. Zaitsev, [Changes in acid-base equilibrium in acute pancreatitis]. Khirurgiia (Mosk), 1968. 44(6): p. 22-6.

5. Sharma, V., et al., Arterial pH, bicarbonate levels and base deficit at presentation as markers of predicting mortality in acute pancreatitis: a single-centre prospective study. Gastroenterol Rep (Oxf), 2014. 2(3): p. 226-31.

6. Guidet, B., et al., A balanced view of balanced solutions. Crit Care, 2010. 14(5): p. 325.

7. Martin, M., et al., Diagnosis of acid-base derangements and mortality prediction in the trauma intensive care unit: the physiochemical approach. J Trauma, 2005. 58(2): p. 238-43.

8. Figge, J., T. Mydosh, and V. Fencl, Serum proteins and acid-base equilibria: a follow-up. J Lab Clin Med, 1992. 120(5): p. 713-9.

9. Kellum, J.A., D.J. Kramer, and M.R. Pinsky, Strong ion gap: a methodology for exploring unexplained anions. J Crit Care, 1995. 10(2): p. 51-5.

10. Story, D.A., H. Morimatsu, and R. Bellomo, Strong ions, weak acids and base excess: a simplified Fencl-Stewart approach to clinical acid-base disorders. Br J Anaesth, 2004. 92(1): p. 54-60.

11. Kaplan, L.J. and J.A. Kellum, Initial $p H$, base deficit, lactate, anion gap, strong ion difference, and strong ion gap predict outcome from major vascular injury. Crit Care Med, 2004. 32(5): p. 1120-4.

12. Leskovan, J.J., et al., Anion gap as a predictor of trauma outcomes in the older trauma population: correlations with injury severity and mortality. Am Surg, 2013. 79(11): p. 1203-6.

13. Maciel, A.T. and M. Park, Unmeasured anions account for most of the metabolic acidosis in patients with hyperlactatemia. Clinics (Sao Paulo), 2007. 62(1): p. 55-62.

14. Bockus, H.L., J.L. Roth, and R.A. Sifre, Diagnosis and treatment of acute pancreatitis. Surg Clin North Am, 1951: p. 1583-601.

15. Banks, P.A., et al., Classification of acute pancreatitis--2012: revision of the 
Atlanta classification and definitions by international consensus. Gut, 2013. 62(1): p. 102-11.

16. Marshall, J.C., et al., Multiple organ dysfunction score: a reliable descriptor of a complex clinical outcome. Crit Care Med, 1995. 23(10): p. 1638-52.

17. Moviat, M., F. van Haren, and H. van der Hoeven, Conventional or physicochemical approach in intensive care unit patients with metabolic acidosis. Crit Care, 2003. 7(3): p. R41-5.

18. Siggaard-Andersen, O., The acid-base status of the blood. Scand J Clin Lab Invest, 1963. 15 Suppl 70: p. 1-134.

19. Stewart, P.A., Modern quantitative acid-base chemistry. Can J Physiol Pharmacol, 1983. 61(12): p. 1444-61.

20. Ouellet, J.F., et al., Admission base deficit and lactate levels in Canadian patients with blunt trauma: are they useful markers of mortality? J Trauma Acute Care Surg, 2012. 72(6): p. 1532-5.

21. Neville, A.L., et al., Mortality risk stratification in elderly trauma patients based on initial arterial lactate and base deficit levels. Am Surg, 2011. 77(10): p. 1337-41.

22. Rutherford, E.J., et al., Base deficit stratifies mortality and determines therapy. J Trauma, 1992. 33(3): p. 417-23.

23. Stewart, C.L., et al., Base deficit correlates with mortality in pediatric abusive head trauma. J Pediatr Surg, 2013. 48(10): p. 2106-11.

24. Brill, S.A., et al., Base deficit does not predict mortality when secondary to hyperchloremic acidosis. Shock, 2002. 17(6): p. 459-62.

25. Moviat, M., et al., Stewart analysis of apparently normal acid-base state in the critically ill. J Crit Care, 2013. 28(6): p. 1048-54.

26. Story, D.A., S. Poustie, and R. Bellomo, Comparison of three methods to estimate plasma bicarbonate in critically ill patients: Henderson-Hasselbalch, enzymatic, and strong-ion-gap. Anaesth Intensive Care, 2001. 29(6): p. 585-90.

27. Cusack, R.J., et al., The strong ion gap does not have prognostic value in critically ill patients in a mixed medical/surgical adult ICU. Intensive Care Med, 2002. 28(7): p. 864-9.

28. Antonini, B., et al., The early phase of critical illness is a progressive acidic state due to unmeasured anions. Eur J Anaesthesiol, 2008. 25(7): p. 566-71.

29. Funk, G.C., et al., The strong ion gap and outcome after cardiac arrest in patients treated with therapeutic hypothermia: a retrospective study. Intensive Care Med, 2009. 35(2): p. 232-9.

30. Durward, A., et al., The strong ion gap predicts mortality in children following cardiopulmonary bypass surgery. Pediatr Crit Care Med, 2005. 6(3): p. 281-5.

31. Uchikov, A.P., et al., Blood-gas and acid-base profile in dogs with severe 
pancreatitis. Folia Med (Plovdiv), 2003. 45(1): p. 33-6.

32. Ambartsumian, R.G. and V.G. Zaitsev, [The acid-base equilibrium and the level of lactic and pyruvic acids in the blood in patients with acute pancreatitis]. Klin Med (Mosk), 1968. 46(7): p. 106-10.

33. Kellum, J.A., et al., Hepatic anion flux during acute endotoxemia. J Appl Physiol (1985), 1995. 78(6): p. 2212-7.

34. Wang, G.J., et al., Acute pancreatitis: etiology and common pathogenesis. World J Gastroenterol, 2009. 15(12): p. 1427-30.

35. Dellinger, E.P., et al., Determinant-based classification of acute pancreatitis severity: an international multidisciplinary consultation. Ann Surg, 2012. 256(6): p. 875-80.

36. Zheng, C.M., et al., Metabolic acidosis and strong ion gap in critically ill patients with acute kidney injury. Biomed Res Int, 2014. 2014: p. 819528.

37. Moviat, M., et al., Contribution of various metabolites to the "unmeasured" anions in critically ill patients with metabolic acidosis. Crit Care Med, 2008. 36(3): p. 752-8. 


\section{Figure legends:}

Figure 1. Screening of the study patients

Figure 2. Box and whisker plots for lactate, standard base excess (SBE), strong ion gap (SIG) and anion gap (AG) in patients of mild-moderate and severe groups on admission. All the three variables were significantly different between groups ( $p<0.001$ for SBE, SIG and AG, $p=0.003$ for lactate). Values were median \pm IQR.

Figure 3. The Receiver Operating Characteristic (ROC) curve of SIG and APACHE II score in predicting AP severity. 
Table 1. Demographic characteristics and outcomes of the study patients according to severity ${ }^{a}$

\begin{tabular}{|c|c|c|c|c|}
\hline Variable & $\begin{array}{l}\text { Mild-Moderate } \\
(\mathrm{n}=101)\end{array}$ & $\begin{array}{l}\text { Severe } \\
(\mathrm{n}=85)\end{array}$ & $\begin{array}{l}\text { Total } \\
(n=186)\end{array}$ & $\mathrm{P}$ \\
\hline Age, years & $46(36,60)$ & $46(37,56)$ & $46(37,59)$ & 0.467 \\
\hline Gender, male/female & $66 / 35$ & $60 / 25$ & $126 / 60$ & 0.446 \\
\hline BMI, $\mathrm{kg} / \mathrm{m}^{2}$ & $\begin{array}{l}25.4 \\
27.7)\end{array}$ & $\begin{array}{l}27.1 \quad(24.4, \\
30.0) \quad\end{array}$ & $\begin{array}{l}26.0 \quad(23.4 \\
28.5)\end{array}$ & 0.030 \\
\hline APACHE II score & $12(11,14)$ & $18(14,26)$ & $14(12,18)$ & $<0.001$ \\
\hline BISAP score & $2(2,3)$ & $3(2,3)$ & $2(2,3)$ & $<0.001$ \\
\hline SOFA score & $3(2,3)$ & $6(3,9)$ & $3(2,6)$ & $<0.001$ \\
\hline CT severity index & $6(6,8)$ & $10(8,10)$ & $8(6,10)$ & $<0.001$ \\
\hline $\begin{array}{l}\text { Sterile necrotic } \\
\text { pancreatitis, no. }(\%)\end{array}$ & $28(27.7)$ & $43(50.6)$ & $71(38.2)$ & 0.001 \\
\hline $\begin{array}{l}\text { Infected necrotic } \\
\text { pancreatitis, no. }(\%)\end{array}$ & $5(5.0)$ & $41(48.2)$ & $46(24.7)$ & $<0.001$ \\
\hline $\begin{array}{l}\text { Aetiology of acute } \\
\text { pancreatitis, no. }(\%)\end{array}$ & & & & \\
\hline Biliary & $57(56.4)$ & $34(40.0)$ & $91(48.9)$ & 0.026 \\
\hline Alcohol & $2(2.0)$ & $3(3.5)$ & $5(2.7)$ & 0.515 \\
\hline Hypertriglyceridemia & $31(30.7)$ & $45(52.9)$ & $76(40.9)$ & 0.002 \\
\hline Pregnancy & $6(5.9)$ & $3(3.5)$ & $9(4.8)$ & 0.445 \\
\hline Post-ERCP & $2(2.0)$ & $0(0)$ & $2(1.1)$ & 0.192 \\
\hline Other & $2(2.0)$ & $1(1.2)$ & $3(1.6)$ & 0.665 \\
\hline \multicolumn{5}{|l|}{ Co-morbidities, no. (\%) } \\
\hline Hypertension & $58(57.4)$ & $40(47.0)$ & $98(52.7)$ & 0.158 \\
\hline Diabetes mellitus & $47(46.5)$ & $38(44.7)$ & $85(45.7)$ & 0.803 \\
\hline Fatty liver & $33(32.7)$ & $46(54.1)$ & $79(42.5)$ & 0.003 \\
\hline Coronary & $5(5.0)$ & $4(4.7)$ & $9(4.8)$ & 0.938 \\
\hline \multicolumn{5}{|l|}{ Disease } \\
\hline Organ failure, no. $(\%)$ & Transient & $\begin{array}{l}\text { Transient } \\
\text { and/or } \\
\text { persistent }\end{array}$ & $\begin{array}{l}\text { Transient } \\
\text { and/or } \\
\text { persistent }\end{array}$ & \\
\hline Respiratory & $11(10.9)$ & $75(88.2)$ & $86(46.2)$ & $<0.001$ \\
\hline Renal & $5(5.0)$ & $60(70.6)$ & $65(34.9)$ & $<0.001$ \\
\hline Cardiovascular & $1(1.0)$ & $32(37.6)$ & $33(17.7)$ & $<0.001$ \\
\hline \multicolumn{5}{|l|}{ Complication, no. (\%) } \\
\hline Pancreatic pseudocyst & $4(4.0)$ & $5(5.9)$ & $9(4.8)$ & 0.543 \\
\hline
\end{tabular}




\begin{tabular}{|c|c|c|c|c|}
\hline Invasive & $0(0)$ & $5(5.9)$ & $5(2.7)$ & 0.013 \\
\hline \multicolumn{5}{|l|}{ infection } \\
\hline Intra-abdominal & $1(1.0)$ & $21(24.7)$ & $22(11.8)$ & $<0.001$ \\
\hline \multicolumn{5}{|l|}{ hemorrhage } \\
\hline Deep vein thrombosis & $1(1.0)$ & $8(9.4)$ & $9(4.8)$ & 0.008 \\
\hline Portal thrombosis & $1(1.0)$ & $4(4.7)$ & $5(2.7)$ & 0.119 \\
\hline IAH & $0(0)$ & $18(21.2)$ & $18(9.7)$ & $<0.001$ \\
\hline Encephalopathy & $0(0)$ & $4(4.7)$ & $4(2.2)$ & 0.028 \\
\hline Fistula & $0(0)$ & $12(14.1)$ & $12(6.4)$ & $<0.001$ \\
\hline Hospital stay, days & $9(6,11)$ & $21(13,38)$ & $12(7,22)$ & $<0.001$ \\
\hline ICU stay, days & $5(3,8)$ & $15(7,36)$ & $7(4,15)$ & $<0.001$ \\
\hline Mortality, no. (\%) & $0(0)$ & $33(38.8)$ & $33(17.7)$ & $<0.001$ \\
\hline
\end{tabular}

aBMI: body mass index; APACHE II score: Acute Physiology and Chronic Health Enquiry II score; BISAP: Bedside Index For Severity In Acute Pancreatitis; SOFA: Sequential Organ Failure Assessment; CT: Computed Tomography; ERCP: endoscopic retrograde cholangiopancreatography; IAH: intra-abdominal hypertension; ICU: intensive care unit. 
Table 2. Acid-base evaluation according to severity ${ }^{\text {a }}$

\begin{tabular}{|c|c|c|c|c|}
\hline Variable & $\begin{array}{l}\text { Mild-Moderate } \\
(\mathrm{n}=101)\end{array}$ & $\begin{array}{l}\text { Severe } \\
(\mathrm{n}=85)\end{array}$ & Volunteers $(n=13)$ & $\mathrm{P}^{*}$ \\
\hline $\mathrm{pH}$ & $7.42(7.40,7.45)$ & $7.39(7.34,7.43)$ & $7.41(7.40,7.43)$ & $<0.001$ \\
\hline $\mathrm{PaCO}_{2}, \mathrm{mmHg}$ & $33.4(30.8,36.8)$ & $32.0(27.8,36.4)$ & $40.4(38.0,42.3)$ & 0.118 \\
\hline $\mathrm{SBE}, \mathrm{mEq} / \mathrm{L}$ & $-1.8(-4.2,-0.4)$ & $-5.0(-9.0,-2.3)$ & $1.0(-0.7,1.6)$ & $<0.001$ \\
\hline $\mathrm{AG}, \mathrm{mEq} / \mathrm{L}$ & $10.7(8.4,12.1)$ & $15.6(12.6,18.0)$ & $11.6(11.1,12.4)$ & $<0.001$ \\
\hline $\mathrm{AG}_{\text {corr }}, \mathrm{mEq} / \mathrm{L}$ & $9.6(8.0,11.4)$ & $15.1(12.7,17.1)$ & $8.9(8.5,9.6)$ & $<0.001$ \\
\hline Lactate, $\mathrm{mmol} / \mathrm{L}$ & $1.3(0.9,2.0)$ & $1.8(1.2,2.6)$ & $0.6(0.6,0.7)$ & 0.003 \\
\hline SIDa, mEq/L & $35.9(33.6,38.4)$ & $38.0(34.8,40.4)$ & $39.9(38.0,40.9)$ & 0.009 \\
\hline SIDe, mEq/L & $33.6(31.1,35.2)$ & $29.3(25.8,32.9)$ & $40.1(38.0,40.4)$ & $<0.001$ \\
\hline $\mathrm{SIG}, \mathrm{mEq} / \mathrm{L}$ & $2.11(0.97,4.15)$ & $7.88(5.25,10.00)$ & $0.22(-0.50,0.84)$ & $<0.001$ \\
\hline $\mathrm{Na}^{+}, \mathrm{mmol} / \mathrm{L}$ & $135(133,137)$ & $139(135,143)$ & $138(137,139)$ & $<0.001$ \\
\hline $\mathrm{K}^{+}, \mathrm{mmol} / \mathrm{L}$ & $3.9(3.6,4.2)$ & $4.1(3.6,4.6)$ & $3.9(3.8,4.0)$ & 0.002 \\
\hline $\mathrm{Cl}^{-}, \mathrm{mmol} / \mathrm{L}$ & $105(102,109)$ & $108(104,111)$ & $104(104,106)$ & 0.008 \\
\hline $\mathrm{iCa}^{++}, \mathrm{mmol} / \mathrm{L}$ & $1.07(1.00,1.12)$ & $0.96(0.81,1.11)$ & $1.19(1.18,1.21)$ & 0.001 \\
\hline $\mathrm{Mg}^{++}, \mathrm{mmol} / \mathrm{L}$ & $0.80(0.70,0.90)$ & $0.70(0.60,0.90)$ & $0.60(0.58,0.69)$ & 0.329 \\
\hline Phos, mmol/L & $0.90(0.70,1.10)$ & $0.90(0.60,1.27)$ & $1.02(0.93,1.11)$ & 0.406 \\
\hline $\mathrm{HCO}_{3}^{-}, \mathrm{mmol} / \mathrm{L}$ & $23.2(21.6,24.4)$ & $20.2(18.0,22.6)$ & $25.2(24.0,25.8)$ & $<0.001$ \\
\hline Albumin, g/L & $36.0(34.8,39.4)$ & $33.9(30.8,35.9)$ & $47.8(46.1,48.5)$ & $<0.001$ \\
\hline Hematocrit, \% & $45.5(41.0,50.0)$ & $51.0(46.0,59.0)$ & $39.3(34.6,41.6)$ & $<0.001$ \\
\hline Hemoglobin, g/L & $137(118,153)$ & $122(96,146)$ & $154(137,158)$ & 0.001 \\
\hline $\mathrm{BUN}, \mathrm{mmol} / \mathrm{L}$ & $5.2(4.0,6.8)$ & $9.7(5.8,14.0)$ & - & $<0.001$ \\
\hline Creat, $\mu \mathrm{mol} / \mathrm{L}$ & $61(50,72)$ & $108(62,211)$ & - & $<0.001$ \\
\hline Platelet, $\times 10^{9} / \mathrm{L}$ & $160(118,199)$ & $133(88,206)$ & - & 0.483 \\
\hline
\end{tabular}

${ }^{\text {a SBE}}$ : standard base excess; AG: anion gap; SIDa: apparent strong ion difference; SIDe: effective strong ion difference; SIG: strong ion gap; BUN: blood urea nitrogen; Creat: creatinine.

*Mild-moderate vs. Severe AP 
Table 3. Multivariate stepwise logistic regression and AUROC for acid-base variables to predict severity ${ }^{\mathrm{a}}$

\begin{tabular}{lllll}
\hline Element & OR $(95 \% \mathrm{CI})$ & $\mathrm{P}$ & AUROC $(95 \% \mathrm{CI})$ & $\mathrm{P}$ \\
\hline SOFA score & $1.34(1.08-1.72)$ & 0.006 & $0.82(0.76-0.88)$ & $<0.001$ \\
SIG & $1.56(1.29-1.89)$ & $<0.001$ & $0.91(0.86-0.95)$ & $<0.001$ \\
APACHE II score & $1.61(1.28-2.01)$ & $<0.001$ & $0.87(0.81-0.92)$ & $<0.001$ \\
$\mathrm{Na}^{+}$ & $1.14(1.01-1.30)$ & 0.032 & $0.71(0.63-0.79)$ & $<0.001$ \\
\hline
\end{tabular}

aAUROC: area under the ROC curves; OR: odds ratio; CI: confidence interval; SOFA: Sequential Organ Failure Assessment; SIG: strong ion gap; APACHE II: Acute Physiology and Chronic Health Enquiry II. 
Table 4. Univariate and multivariate analyses of factors associated with SIG levels $^{\mathrm{a}}$

\begin{tabular}{|c|c|c|c|c|c|c|}
\hline & \multicolumn{3}{|c|}{ Univariate analysis } & \multicolumn{3}{|c|}{ Multivariate analysis } \\
\hline & OR & $95 \% \mathrm{CI}$ & $\mathrm{P}$ & OR & $95 \% \mathrm{CI}$ & $\mathrm{P}$ \\
\hline SBE, $\mathrm{mEq} / \mathrm{L}$ & -0.379 & -0.486 to -0.273 & $<0.001$ & -0.80 & -0.93 to -0.67 & $<0.001$ \\
\hline $\mathrm{AG}, \mathrm{mEq} / \mathrm{L}$ & 0.742 & 0.672 to 0.812 & $<0.001$ & & & \\
\hline $\mathrm{AG}_{\mathrm{corr}}, \mathrm{mEq} / \mathrm{L}$ & 0.830 & 0.775 to 0.886 & $<0.001$ & 0.89 & 0.85 to 0.94 & $<0.001$ \\
\hline Lactate, $\mathrm{mmol} / \mathrm{L}$ & 0.782 & 0.259 to 1.306 & 0.004 & & & \\
\hline Phos, mmol/L & 1.794 & 0.456 to 3.131 & 0.009 & -1.89 & -2.32 to -1.47 & $<0.001$ \\
\hline $\mathrm{HCO}_{3}{ }^{-}, \mathrm{mmol} / \mathrm{L}$ & -0.497 & -0.634 to -0.361 & $<0.001$ & 0.88 & 0.71 to 1.06 & $<0.001$ \\
\hline Albumin, $g / L$ & -0.418 & -0.551 to -0.284 & $<0.001$ & -0.05 & -0.10 to -0.01 & 0.022 \\
\hline $\mathrm{BUN}, \mathrm{mmol} / \mathrm{L}$ & 0.262 & 0.164 to 0.361 & $<0.001$ & & & \\
\hline Creat, $\mu \mathrm{mol} / \mathrm{L}$ & 0.014 & 0.009 to 0.020 & $<0.001$ & & & \\
\hline
\end{tabular}

a SIG: strong ion gap; OR: odds ratio; CI: confidence interval; SBE: standard base excess; AG: anion gap; Phos: phosphate; BUN: blood urea nitrogen; Creat: creatinine. 


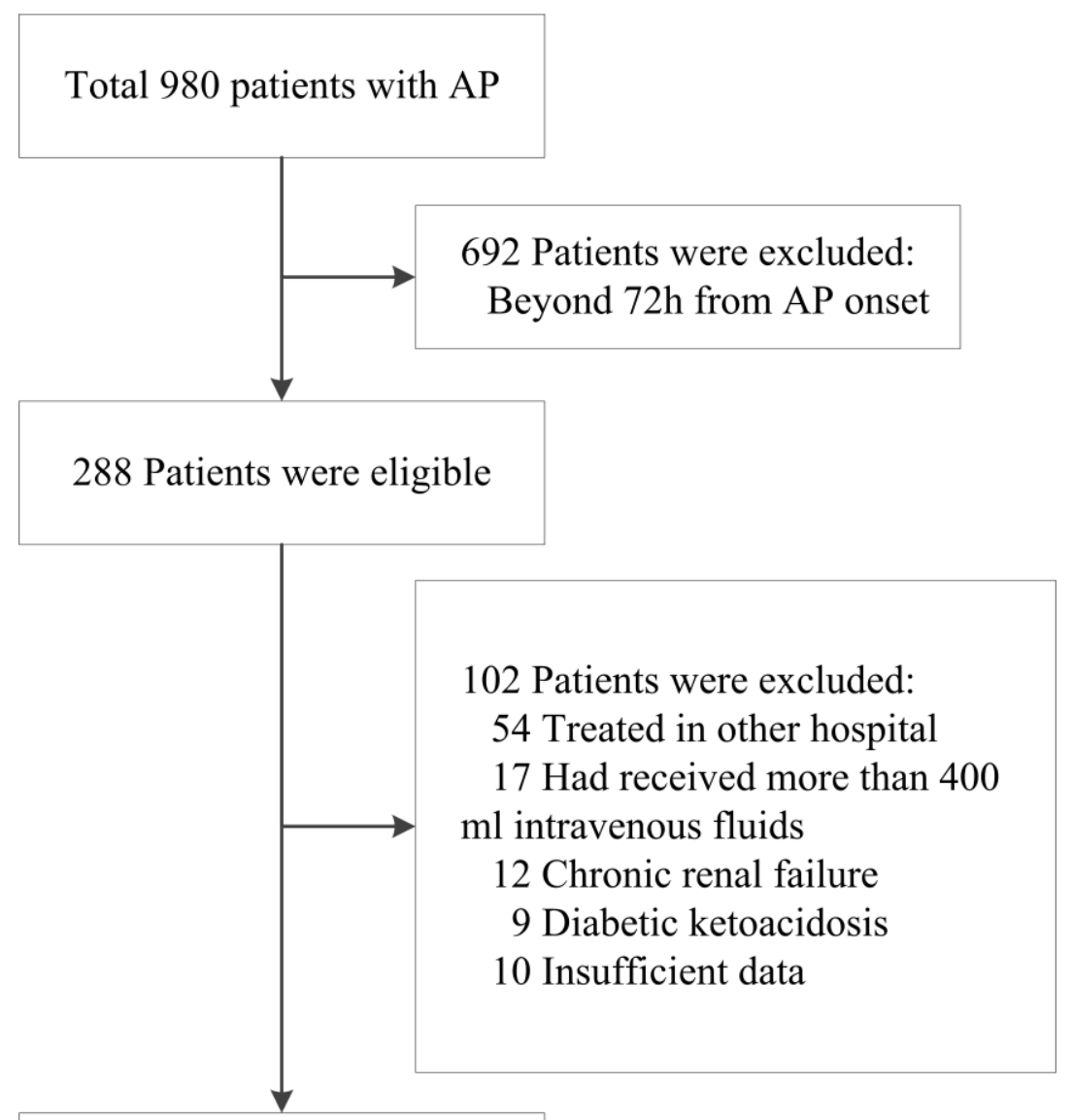

186 Patients were included and analysed 


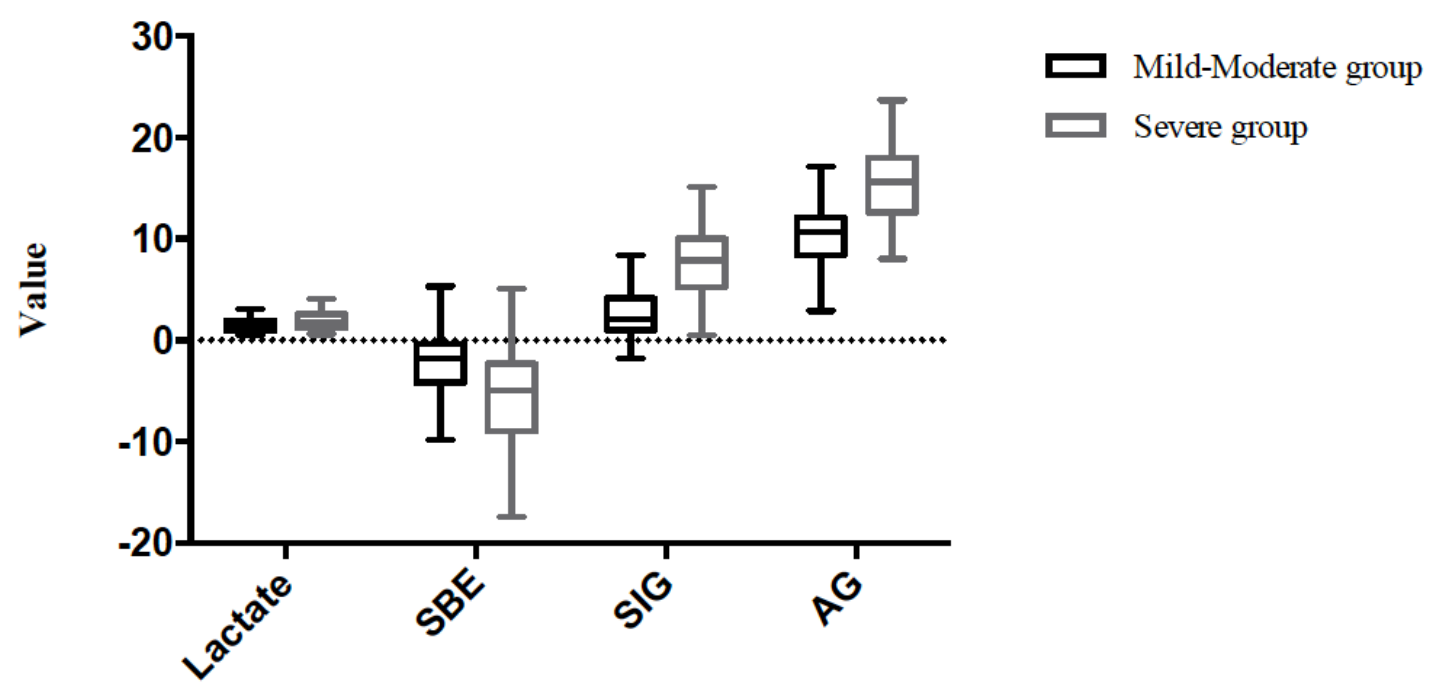

Variable 


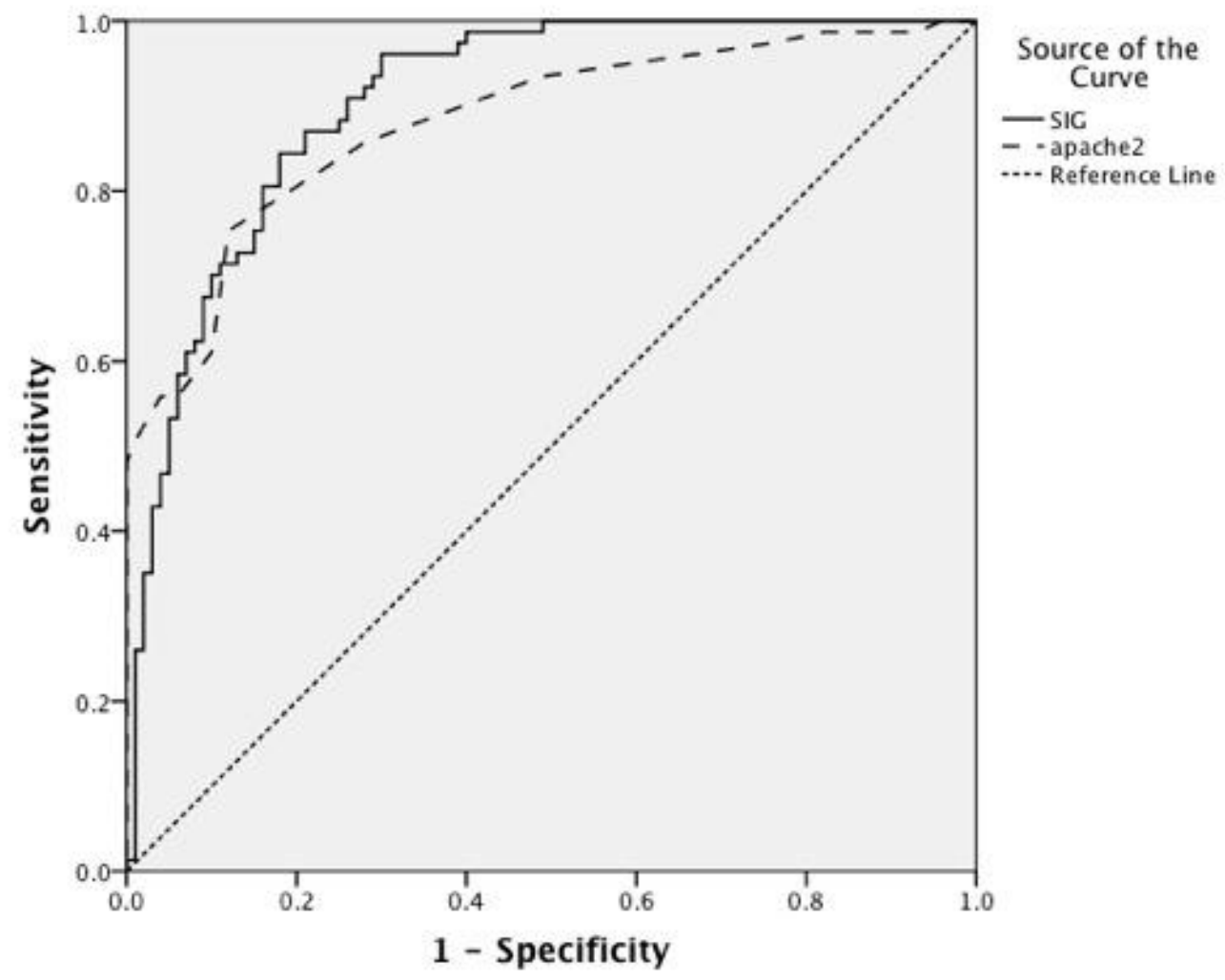

Prognostic value of SIG in AP 